\section{JTI}

JOURNAL OF

TRAUMA AND INJURY

\title{
Comments on "Case Series: Successful Resuscitation of Severe Facial Injuries Caused by a Chainsaw"
}

\author{
Kun Hwang, M.D., Ph.D. \\ Department of Plastic Surgery, Inha University School of Medicine, Incheon, Korea
}

Received: November 12, 2019

Accepted: November 12, 2019

\section{Correspondence to}

Kun Hwang, M.D., Ph.D.

Department of Plastic Surgery, Inha University Hospital, 27 Inhang-ro, Jung-gu,

Incheon 22332, Korea

Tel: $+82-32-890-3514$

Fax: +82-32-890-2918

E-mail: jokerhg@inha.ac.kr
These comments refer to a paper recently published in JTI [1].

I read the paper with interest. However, several questions remain which cannot be solved by author's descriptions.

In case 1, the patient had an open mandibular fracture with massive bone and soft tissue loss, and deep lacerations of the tongue. In Fig. 2B of Choi [1], I cannot see if the patient regained his occlusions. Could I see the pre-op and post op X-rays and his teeth applying mouth gag?

In case 2, the patient had deep laceration on the medial side of left upper eyelid (Fig. 3A of Choi [1]). In a glance, lacrimal canalicular injury is highly suspected. In Fig. 3B of Choi [1], I cannot see the patient's eye including medial canthus because they were shielded. Did he have any problem in his lacrimal system postoperatively? Did he have any difficulty in closing or opening his eyes postoperatively? According to the paper which Dr Choi did not cite, $47 \%$ incidence of lacrimal obstruction is reported after naso-ethmoid0-orbital fractures caused from chainsaw injuries [2].

In the literature, relatively high incidence of chainsaw injury was reported in the maxillofacial region. From the 19-year report of Serbia, among the 133 saw injuries of the maxillofacial region, chainsaw injury occupied $23 \%$ (30 cases) [3]. Lastly, I would like to emphasize the corporation of the plastic surgeon and trauma surgeon for the patients who have maxillofacial injuries.

\section{REFERENCES}

1. Choi HJ. Case series: successful resuscitation of severe facial injuries caused by a chainsaw. J Trauma Inj 2019;32:168-71.

2. Craft RO, Eberlin KR, Stella MH, Caterson EJ. Management of extensive maxillofacial trauma 
Kun Hwang, et al. Chainsaw Caused Facial Injuries

with bony foreign body within the orbit from a chainsaw injury. Eplasty 2011;11:e44.

3. Konstantinović VS, Puzović D, Anicić B, Jelovac DB. Epidemi- ological, clinical, and forensic aspects of chainsaw, circular saw, and grinding saw injuries in the maxillofacial region. J Craniofac Surg 2010;21:1029-32. 